\title{
Human cytomegalovirus miR-US4-5p promotes apoptosis via downregulation of p21-activated kinase 2 in cultured cells
}

\author{
YAOZHONG SHAO $^{1,2}$, YING QI ${ }^{1}$, YUJING HUANG ${ }^{1}$, ZHONGYANG LIU $^{1}$, YANPING MA ${ }^{1}$, \\ XIN GUO ${ }^{1}$, SHUJUAN JIANG ${ }^{1}$, ZHENGRONG SUN ${ }^{1}$ and QIANG RUAN ${ }^{1}$ \\ ${ }^{1}$ Virus Laboratory, Affiliated Shengjing Hospital, China Medical University, Shenyang, Liaoning 110004; \\ ${ }^{2}$ Nephrology Department, First Affiliated Hospital of Medicine School, Xi'an, Jiaotong University, Xi'an, Shanxi 710061, P.R. China
}

Received March 23, 2016; Accepted May 23, 2017

DOI: $10.3892 / \mathrm{mmr} .2017 .7108$

\begin{abstract}
The human cytomegalovirus (HCMV) encodes $\geq 26$ microRNAs (miRNAs). These miRNAs are utilized by HCMV to regulate its own genes in addition to the genes of the host cell, during infection. The present study first identified p21-activated kinase 2 (PAK2) as a target of hcmv-miR-US4-5p, via hybrid polymerase chain reaction, which was further verified using a luciferase reporter assay. The protein expression level of PAK2, detected via western blotting, was demonstrated to be directly downregulated by overexpression of hcmv-miR-US4-5p in HEK293, HELF and THP-1 cells. Furthermore, it was demonstrated that the PAK2 protein level in naturally infected HELF cells was gradually decreased at 24, 48 and $72 \mathrm{~h}$ post infection with increased hcmv-miR-US4-5p expression. The use of PAK2-specific small interfering RNA and an inhibitor for hcmv-miR-US4-5p, demonstrated that the promotion of apoptosis by hcmv-miR-US4-5p in these cells was specifically mediated via inhibition of PAK2 expression. These results indicated that homv-miR-US4-5p may exhibit this activity during natural HCMV infection, in order to establish a balance between the host cell and virus.
\end{abstract}

\section{Introduction}

Human cytomegalovirus (HCMV) is a ubiquitous $\beta$-herpes virus that may result in significantly greater levels of morbidity and mortality in congenitally infected newborns and immunocompromised patients (1). HCMV encompasses a $230 \mathrm{~kb}$ genome and encodes $\geq 26$ mature microRNAs (miRNAs) from 16 precursors (2). Post-transcriptional regulation by miRNAs on their target mRNAs is achieved via specific base-pair binding between nucleotides located at positions 2-7 at the 5' end of

Correspondence to: Dr Qiang Ruan, Virus Laboratory, Affiliated Shengjing Hospital, China Medical University, 36 San Hao Street, Shenyang, Liaoning 110004, P.R. China

E-mail: ruanq@sj-hospital.org

Key words: human cytomegalovirus, microRNAs, homv-miR-US4-5p, p21-activated kinase 2, pro-apoptotic the miRNA (termed, the seed region) and the $3^{\prime}$ untranslated region (3'UTR) of target mRNAs, leading to the translational repression and decay of the specific target mRNA (3). Previous studies have suggested that viral miRNAs may be associated with immune evasion, latency of herpes virus subfamilies and cell apoptosis (4-6). As an miRNA derived from the precursor hcmv-miR-US4, hcmv-miR-US4-5p was first identified by deep sequencing analysis of small RNAs from infected human fibroblast cells (7). However, its particular function remains to be elucidated.

The present study identified p21-activated kinase 2 (PAK2) as a direct target of hcmv-miR-US4-5p. Downregulation of PAK2 expression by hcmv-miR-US4-5p, or its specific small interfering (si)RNA, promoted cell apoptosis in multiple cells. These results suggested that promotion of cell apoptosis by overexpression of hcmv-miR-US4-5p specifically occurs via downregulation of PAK2 expression.

\section{Materials and methods}

Cell culture and virus. The HEK293 human embryonic kidney cells and the HELF human embryonic lung fibroblast cells were acquired from the Shanghai Institute for Biological Sciences, Chinese Academy of Sciences (Shanghai, China). The THP-1 human monocytic cell line was presented by Professor Minhua Luo from the Wuhan Institute of Virology, Chinese Academy of Sciences (Wuhan, China). The HEK293, HELF and THP-1 cells were cultured respectively in Dulbecco's modified Eagle's medium (DMEM), modified Eagle's medium (MEM) and RPMI-1640 medium (1640), which were supplemented with $10 \%$ fetal bovine serum (FBS) (HyClone; GE Healthcare, Chicago, IL, USA), 100 units/ml penicillin and 100 units/ml streptomycin sulfate. All cell cultures were maintained at $37^{\circ} \mathrm{C}$ in an incubator in an environment containing $5 \% \mathrm{CO}_{2}$. The HELF cells used in this study were on passages 10-15. The HCMV clinical strain Han (GenBank; accession no. KJ426589.1) was isolated from a urine sample of a 5-month-old infant hospitalized in the Affiliated Shengjing Hospital, China Medical University (Shenyang, China). HELF cells were infected with the Han strain and the infected cells were collected 5-7 days post infection. Following freezing and thawing three times, the infectious particles in the recovered supernatants were titrated with a $50 \%$ tissue culture infective 
dose assay by counting the cytopathic effect at 11 days post infection (pi). The titrated virus was stored at $-80^{\circ} \mathrm{C}$ prior to use. To propagate the virus, HELF cells were inoculated with the Han strain at 1 multiplicity of infection (MOI) and maintained in MEM supplemented with 2\% FBS and penicillin-streptomycin. The cell lysate was then harvested and stored at $-80^{\circ} \mathrm{C}$ prior to use.

Hybrid-polymerase chain reaction $(P C R)$ and online prediction. HELF cells were inoculated with the Han strain at 1 MOI and harvested at $48 \mathrm{~h}$ pi. Total RNA was extracted with TRIzol $^{\circledR}$ (Invitrogen; Thermo Fisher Scientific, Inc., Waltham, MA, USA) and treated with the TURBO DNA-free ${ }^{\mathrm{TM}} \mathrm{Kit}$ (Ambion; Thermo Fisher Scientific, Inc.). Hybrid-PCR was performed as previously described (8) using 3'-Full RACE Core Set (Takara Biotechnology Co., Ltd., Dalian, China). The hybrid primer (5'-CRGRCRTCCCCCTGCRCGTCCR-3') for hcmv-miR-US4-5p was designed according to the miRNA sequence (5'-UGGACGUGCAGGGGGAUGUCUG-3'). The ' $R$ ' in the hcmv-miR-US4-5p hybrid primer indicates random insertions of adenine (A) or guanine $(\mathrm{G})$. Cycling conditions were as follows: Hybrid-PCR was hot started at $72^{\circ} \mathrm{C}$, an in initial predenaturation step at $95^{\circ} \mathrm{C}$ for $5 \mathrm{~min}$, followed by 30 cycles of denaturation at $95^{\circ} \mathrm{C}$ for $45 \mathrm{sec}$, annealing at $37^{\circ} \mathrm{C}$ for $45 \mathrm{sec}$ and extension at $72^{\circ} \mathrm{C}$ for $3 \mathrm{~min}$. A total of $1 \mu \mathrm{l}$ product from the first round of amplification was used as a template in the second round of PCR, in which the annealing temperature was increased to $55^{\circ} \mathrm{C}$. All Hybrid-PCR products were harvested using Promega Wizard SV Gel and PCR Clean-up System (Promega Corporation, Madison, WI, USA) and cloned into pMD-19T vectors (Takara Biotechnology Co., Ltd.). The recombinant products, at a concentration of about $10 \mathrm{ng} / \mu \mathrm{l}$, were then transformed into $E$. coli $\mathrm{DH} 5 \alpha$ (9) to produce a target pool with specific sequences of putative target mRNAs for hcmv-miR-US4-5p to bind. For transformation, the frozen cells were thawed on ice, mixed immediately with $5 \mu \mathrm{l}$ recombinant products, and incubated at $4^{\circ} \mathrm{C}$ for $30 \mathrm{~min}$. The cells were then subjected to a heat pulse at $42^{\circ} \mathrm{C}$ for $90 \mathrm{sec}$, then chilled on ice for $2 \mathrm{~min}$, diluted 10 -fold into prewarmed L-broth, and incubated at $37^{\circ} \mathrm{C}$ for $1 \mathrm{~h}$ to allow expression of antibiotic resistance. Samples (10 and $50 \mu \mathrm{l}$ ) were plated on agar plates containing $20 \mu \mathrm{g} / \mathrm{ml}$ of sodium salt of ampicillin. Transformation frequency was calculated on the basis of colony counts after $20 \mathrm{~h}$ incubation at $37^{\circ} \mathrm{C}$. Nineteen clones were randomly selected and plasmids in the clones were extracted. Inserted sequences of the plasmids were sequenced on an ABI 3730 automated sequencer (Applied Biosystems; Thermo Fisher Scientific, Inc.) The mRNA specific sequences located between the hcmv-miR-US4-5p hybrid primer and polyA tails were intercepted and used to identify the putative target genes by BLAST (www.ncbi.nlm.nih.gov/blast). Target prediction was also performed online using Targetscan (www.targetscan.org/).

Plasmid construction. The sequence of the PAK2 3'UTR was obtained via reverse transcription (RT) -PCR from RNA of HELF cells using forward, 5'-CGGACTAGTGCAGTG CCACCTGAGTTC-3' and reverse, 5'-CCCAAGCTTGAA CCCAGGAAGCGGAGG-3' primer sequences. The purified products were inserted into SpeI and HindIII sites of the multiple cloning region of the luciferase reporter construct pMIR (Ambion; Thermo Fisher Scientific Fisher, Inc.), resulting in pMIR-PAK2 UTR. A mutant vector, pMIR-PAK2 $\mathrm{UTR}^{\mathrm{MUT}}$, containing three nucleotide mutations of the putative binding site of hcmv-miR-US4-5p was generated from the pMIR-PAK2 UTR using pyrobest DNA polymerase (Takara Biotechnology Co., Ltd.) and a mutant primer of 5'-CTTCGATAGTTACCTGCGCTGCCATTGCTGGCA ACTGAC-3' (mutated nucleotides underlined) using the Site-Directed Gene Mutagenesis Kit (Beyotime Institute of Biotechnology, Haimen, China) according to the manufacturer's protocol. Inserts in all the constructs were sequenced on an ABI 3730 automated sequencer (Applied Biosystems; Thermo Fisher Scientific, Inc.).

Luciferase assay. HEK293 cells were cultured in 24-well plates and cotransfected with $200 \mathrm{ng}$ pMIR-PAK2 UTR and pMIR-PAK2 UTR ${ }^{\text {MUT }}$ together with $100 \mathrm{ng}$ pRL-TK-Renilla-luciferase plasmid (Promega Corporation) and $100 \mathrm{nM}$ hcmv-miR-US4-5p mimics (5'-UGGACGUGC AGGGGGAUGUCUG-3') or miRNA negative control (5'-UUUGUACUACACAAA AGUACUG-3'; Guangzhou RiboBio Co., Ltd., Guangzhou, China) using Lipofectamine 3000 (Invitrogen; Thermo Fisher Scientific, Inc.) according to the manufacturer's protocol. Following $48 \mathrm{~h}$, luciferase activities were measured using the Dual Luciferase Reporter Assay System (Promega Corporation) according to the manufacturer's protocol. All measurements were carried out in triplicate, using Dual Luciferase Reporter Assay System (Promega Corporation) at $48 \mathrm{~h}$ post transfection according to the manufacturer's protocol. To eliminate the effects from different transfection efficiencies in each well, signals were normalized against that of the internal renilla control.

Western blotting. To analyze if PAK2 protein expression was affected by hcmv-miR-US4-5p, HEK293, HELF and THP-1 cells cultured in $60 \mathrm{~mm}$ plates were each transfected respectively with $100 \mathrm{nM}$ miRNA negative control, $100 \mathrm{nM}$ hcmv-miR-US4-5p mimics, $100 \mathrm{nM}$ hcmv-miR-US4-5p mimics coupled with $200 \mathrm{nM}$ microFF ${ }^{\mathrm{TM}}$ hcmv-miR-US4-5p inhibitor (2'-O-methylated antisense miRNA inhibitor; Guangzhou RiboBio Co., Ltd.), and 100 nM siRNA of PAK2 (Sigma-Aldrich; Merck KGaA, Darmstadt, Germany) using Lipofectamine 3000 (Invitrogen; Thermo Fisher Scientific, Inc.) according to the manufacturer's protocol. Proteins of the transfected cells were extracted using Mammalian Protein Extraction Reagent M-PER (Thermo Fisher Scientific, Inc.) at $48 \mathrm{~h}$ post transfection, according to the manufacturer's protocol.

To detect if expression of PAK2 protein was influenced by HCMV infection, HELF cells cultured in $60 \mathrm{~mm}$ tissue culture plates were inoculated with the HCMV Han strain at 3 MOI per cell. At 0 (mock infection), 24, 48 and $72 \mathrm{~h}$ post infection (hpi), proteins were extracted using M-PER and quantified by the bicinchoninic acid assay method.

A total of $50 \mu \mathrm{g}$ proteins were separated on $12 \%$ SDS-PAGE gels and transferred onto polyvinylidene fluoride membranes. The membranes were blocked with $5 \%$ skim milk powder at room temperature for $2 \mathrm{~h}$, and then washed with TTBS four times. The protein expression levels of PAK2 and 
Table I. Putative targets of human cyotomegalovirus-miRNA-US4-5p identified by hybrid-polymerase chain reaction.

\begin{tabular}{lc}
\hline mRNA & Accession no. \\
\hline Homo sapiens mortality factor 4 like 2 (MORF4L2) & NM_001142426 \\
Homo sapiens RNA binding protein, fox-1 homolog (C. elegans) 2 (RBFOX2) & NM_001082577 \\
Homo sapiens nuclear factor I/X (CCAAT-binding transcription factor) (NFIX) & NM_002501 \\
Homo sapiens p21 protein (Cdc42/Rac)-activated kinase 2 (PAK2) & NM_002577
\end{tabular}

Table II. Putative targets of human cyotomegalovirus-miRna-US4-5p.

mRNA

Accession no.

Homo sapiens KCNE1-like (KCNE1L)

NM_012282

Homo sapiens p21 protein (Cdc42/Rac)-activated kinase 2 (PAK2)

NM_002577

Homo sapiens XK, Kell blood group complex subunit-related family, member 5 (XKR5)

Homo sapiens membrane associated guanylate kinase, WW and PDZ domain containing 2 (MAGI2)

NM_001289973

Homo sapiens Sp6 transcription factor (SP6)

Homo sapiens calmodulin 1 (phosphorylase kinase, delta) (CALM1)

NM_001301128

NM_199262

NM_006888

Homo sapiens neuro-oncological ventral antigen 1 (NOVA1)

NM_002515

NM_000945

NM_014838

Homo sapiens zinc finger, BED-type containing 4 (ZBED4)

Predicted by http://www.targetscan.org.

glyceraldehydes-3-phosphate dehydrogenase (GAPDH) were detected using the specific primary antibodies anti-PAK2 (catalog no. ab76293; 1:500; Abcam, Cambridge, MA, USA) and anti-GAPDH (catalog no. 10494-1-AP; 1:500; Protein Tech Group, Inc., Chicago, IL, USA) at a temperature of $4^{\circ} \mathrm{C}$ overnight, followed by incubation at room temperature for $2 \mathrm{~h}$ with a horseradish peroxidase-conjugated goat anti-rabbit (catalog no. ZB-2301; 1:1,000; Beijing Zhongshan Golden Bridge Biotechnology Co., Ltd., Beijing, China) secondary antibody. Proteins on the blots were visualized using an Enhanced Chemiluminescence substrate solution (Pierce; Thermo Fisher Scientific, Inc.) and detected using a ChemiDocTM XRS+ imager (Bio-Rad Laboratories, Inc., Hercules, CA, USA). This experiment was conducted in triplicate.

TaqMan assay. Expression levels of hcmv-miR-US4-5p in cells transfected with hcmv-miR-US4-5p mimics or infected with the HCMV Han strain were detected using TaqMan assays according to the manufacturer's protocol. To evaluate natural expression of hcmv-miR-US4-5p in HCMV infected cells, HELF cells were inoculated with the Han strain at 0.5 MOI. At 0, 24, 48 and $72 \mathrm{~h}$ pi, total RNA was isolated from the HELF cells using the mirVana miRNA isolation kit (Ambion; Thermo Fisher Scientific, Inc.) and treated with the TURBO DNA-free ${ }^{\mathrm{TM}}$ Kit (Ambion; Thermo Fisher Scientific, Inc.). RT was performed using the TaqMan miRNA reverse transcription kit (Applied Biosystems; Thermo Fisher Scientific, Inc.), small RNA-specific primers of hemv-miR-US4-5p and small nucleolar RNA U6 (Applied Biosystems; Thermo Fisher Scientific, Inc.). Quantitative (q)PCR was then conducted to measure the expression of mature hcmv-miR-US4-5p and U6 using the Universal PCR Master Mix kit (Applied Biosystems; Thermo Fisher Scientific, Inc.) and specific TaqMan probes (Applied Biosystems; Thermo Fisher Scientific, Inc.) according to the manufacturer's protocol. Cycling conditions were as follows: An initial predenaturation step at $95^{\circ} \mathrm{C}$ for $10 \mathrm{~min}$, followed by 40 cycles of denaturation at $95^{\circ} \mathrm{C}$ for $15 \mathrm{sec}$ and annealing at $60^{\circ} \mathrm{C}$ for $1 \mathrm{~min}$. The relative expression levels of hcmv-miR-US4-5p were normalized to that of U6 RNA using the $2^{-\Delta \Delta \mathrm{Cq}}$ method (10). The measurements were conducted in triplicate.

Apoptosis assay. To investigate the effects of hcmv-miR-US4-5p on cell apoptosis, $100 \mathrm{nM}$ miRNA negative control, $100 \mathrm{nM}$ hcmv-miR-US4-5p mimic, $100 \mathrm{nM}$ hcmv-miR-US4-5p mimic coupled with $200 \mathrm{nM}$ inhibitor for hcmv-miR-US4-5p, or $100 \mathrm{nM}$ siRNA of PAK2 were transfected respectively into three cell lines including HEK293 cells, HELF cells or THP-1 cells cultured in 6-well plates $\left(1-5 \times 10^{9}\right.$ cells). At $24 \mathrm{~h}$ post-transfection, apoptosis of the cells was induced by culturing with medium (DMEM for HEK293 cells, MEM for HELF cells and RPMI-1640 for THP-1 cells) with $0.1 \%$ FBS. Following $24 \mathrm{~h}$, the cells were washed with PBS and harvested with trypsin without-EDTA. After centrifugation at $1,000 \mathrm{x}$ g for $5 \mathrm{~min}$ at $4^{\circ} \mathrm{C}$, the recovered cells were then analyzed for apoptosis using the Alexa Fluor $^{\circledR} 488$ Annexin V/Dead Cell Apoptosis kit (V13241; Invitrogen; Thermo Fisher Scientific, Inc.), following the manufacturer's protocol, on a flow cytometer (FACS Calibur; BD Biosciences, Franklin Lakes, NJ, USA) and using Flowjo 
A

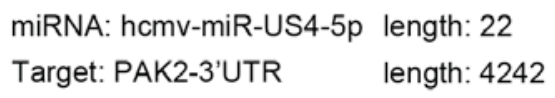

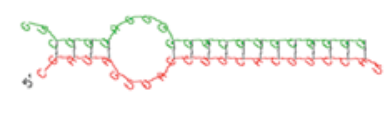

$\mathrm{mfe}:-33.7 \mathrm{kcal} / \mathrm{mol}$
B

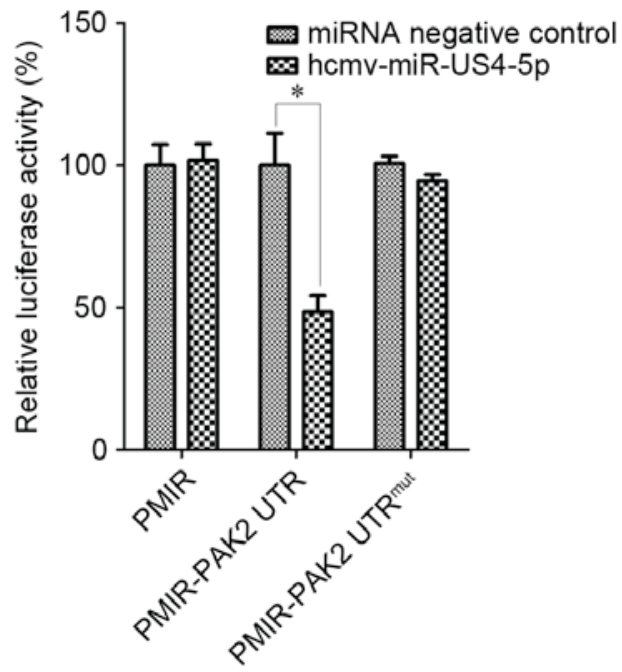

Figure 1. PAK2 is a direct target of hcmv-miR-US4-5p. (A) Schematic diagram of the predicted binding site of hcmv-miR-US4-5p in the PAK2 3'UTR. The predicted binding site of hcmv-miR-US4-5p is located from nt 2240 to 2246 of PAK2 3'UTR. The first nucleotide following the stop codon of PAK2 mRNA is defined as '1'. (B) Dual luciferase assays were performed in HEK 293 cells cotransfected respectively with pMIR-REPORT vector (pMIR), vectors containing the wild type of PAK2 3'UTR (pMIR-PAK2 UTR) and mutant type of PAK2 3'UTR (pMIR-PAK2 UTR ${ }^{\text {MUT }}$ ) together with pRL-TK-Renilla-luciferase plasmid and hcmv-miR-US4-5p mimics or miRNA negative control. The transfection efficiencies were normalized by the renilla luciferase activities in corresponding wells. The assays were performed in triplicate wells. Data from three independent repetitions were used for statistical analysis. "P $<0.05$. nt, nucleotide; PAK2, p21-activated kinase 2; hcmv, human cytomegalovirus; miR, miRNA; UTR, untranslated region; pMIR, pMIR-REPORT vector; pMIR-PAK2 UTR, vectors containing the wild type of PAK2 3'UTR; pMIR-PAK2 UTR ${ }^{\text {MUT }}$ vectors containing the mutant type of PAK2 3'UTR.

software version 7.6.1 (Tree Star, Inc., Ashland, OR, USA). To set up compensation and quadrants, the initial setting of FACS-analysis was based on the fluorescence from blank cells, stained with Alexa Fluor ${ }^{\circledR} 488$ annexin V (Annexin V-FITC) and propidium iodide (PI).

Statistical analysis. SPSS software version 18.0 (SPSS, Inc., Chicago, IL, USA) was used for data analysis, Data from three independent repetitions of each experiment were presented as the mean \pm standard error of the mean and used in the statistical analyses. Statistical significance was determined using a unpaired Student's t-test or an analysis of variance followed by Tukey's post-hoc test. $\mathrm{P}<0.05$ was considered to indicate a statistically significant difference.

\section{Results}

PAK2 is a direct target of hcmv-miR-US4-5p. As presented in Table I, 4 unique cDNA sequences were obtained from 19 clones of hybrid-PCR. Corresponding original mRNAs were successfully identified in GenBank (www.ncbi.nlm.nih.gov/GenBank). A total of 9 target genes of hcmv-miR-US4-5p (Table II) were predicted online using Targetscan (www.targetscan.org/). All putative target mRNAs, including homo sapiens PAK2 mRNA, were from the human genome. PAK2 was the only target predicted online and additionally selected via hybrid-PCR. The binding site of the hcmv-miR-US4-5p seed region was located from nt 2240 to 2246 on the PAK2 3'UTR, the first nucleotide following the stop codon of PAK2 mRNA is defined as 1 , and this was verified using RNAhybrid (http://bibiserv.techfak.uni-bielefeld. de/rnahybrid/submission.html) with minimum free energy (mfe) of $-33.7 \mathrm{kcal} / \mathrm{mol}$ (Fig. 1A).
To assess the binding ability of hcmv-miR-US4-5p to the 3'UTR sequence of PAK 2 mRNA, HEK293 cells were co-transfected with miRNA negative control or hcmv-miR-US4-5p mimic together with pRL-TK-Renilla-luciferase plasmid, and with pMIR-REPORT vector, pMIR-PAK2 UTR and pMIR-PAK2 UTR ${ }^{\mathrm{MUT}}$. As presented in Fig 1B, the renilla normalized firefly luciferase activity of pMIR-PAK2 UTR was significantly decreased $(55 \%)$ in cells co-transfected with hcmv-miR-US4-5p compared with cells co-transfected with miRNA negative control $(" \mathrm{P}<0.001)$. The effect of hcmv-miR-US4-5p on firefly luciferase activity observed in the pMIR-PAK2 UTR was absent in the pMIR-PAK2 UTR ${ }^{\mathrm{MUT}}$, which contained the sequence with triple nucleotide mutations at the putative binding site. These results indicated that homv-miR-US4-5p may directly bind to the predicted binding site in the 3'UTR of PAK2 mRNA.

Expression of PAK2 is downregulated by overexpression of hcmv-miR-US4-5p. To determine if PAK2 expression is affected by homv-miR-US4-5p, the HEK293, HELF and THP-1 cells were transfected with miRNA negative control, hcmv-miR-US4-5p mimic, hcmv-miR-US4-5p mimic coupled with inhibitor for hcmv-miR-US4-5p, and siRNA of PAK2, respectively. Expression levels of PAK2 in the cells were detected via western blotting and the expression of homv-miR-US4-5p in the cells (except for the PAK2 siRNA transfected cells) was examined by TaqMan assay. As demonstrated in the PAK2 siRNA transfected cells, the endogenous PAK2 protein expression level in the HEK293, HELF and THP-1 cells was markedly reduced by overexpression of hemv-miR-US4-5p ("P<0.001; Fig. 2A). The reduction of PAK2 expression by hemv-miR-US4-5p was abolished in cells co-transfected with an inhibitor of homv-miR-US4-5p 
A

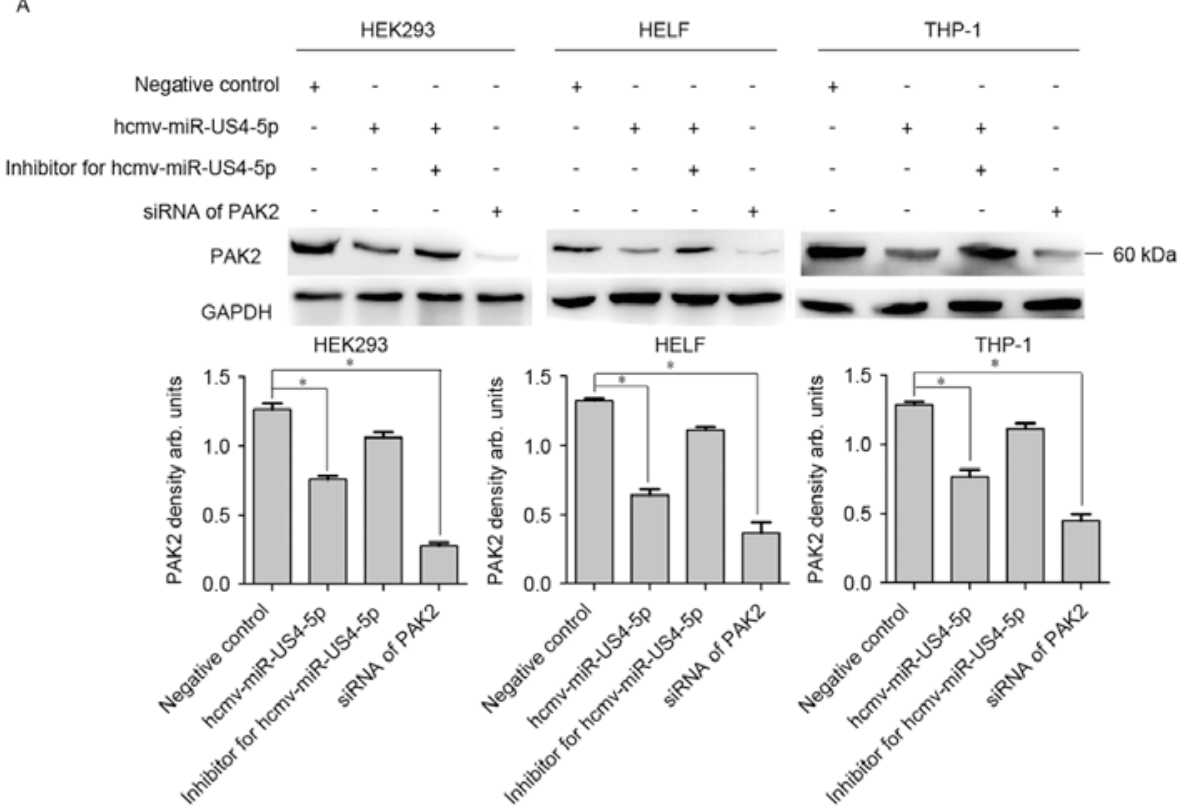

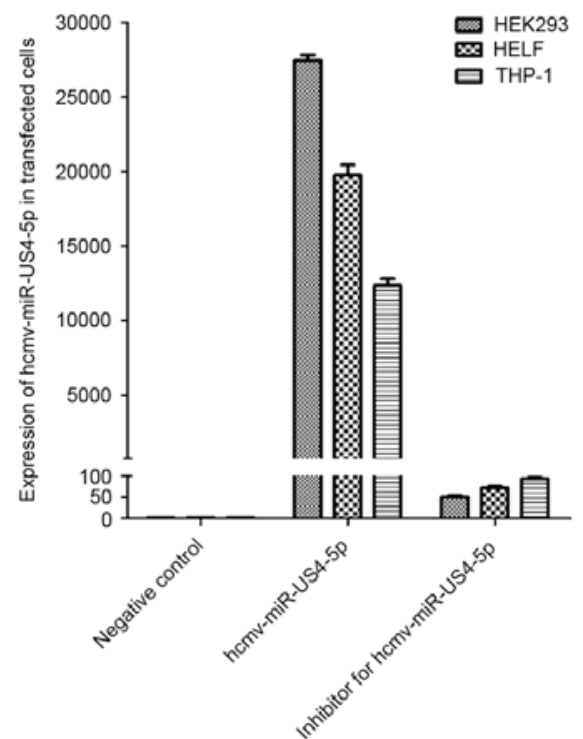

Figure 2. Expression of PAK2 is downregulated by overexpression homv-miR-US4-5p in the three cell types. (A) Expression levels of PAK2 protein (60 kDa) in HEK293, HELF and THP-1 cells transfected respectively with miRNA negative control, hcmv-miR-US4-5p mimics, hcmv-miR-US4-5p mimics coupled with inhibitor for hcmv-miR-US4-5p (inhibitor for hcmv-miR-US4-5p), and siRNAs of PAK2, were detected at $48 \mathrm{~h}$ post transfection by western blot. The relative expression of PAK2 was normalized to those of GAPDH in corresponding samples. The assays were performed in triplicate wells. Data from three independent repetitions were used for statistical analysis. ${ }^{*} \mathrm{P}<0.001$. (B) Expression levels of hcmv-miR-US4-5p in the transfected cells were detected by TaqMan assay. Quantification of hcmv-miR-US4-5p expression was normalized to that of snRNA U6 in corresponding samples by the $2^{-\Delta A C q}$ method. Data from three independent repetitions were recorded and presented. PAK2, p21-activated kinase 2; hcmv, human cytomegalovirus; miR, miRNA; siRNA, small interfering RNA.

A

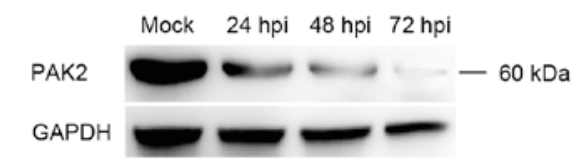

C

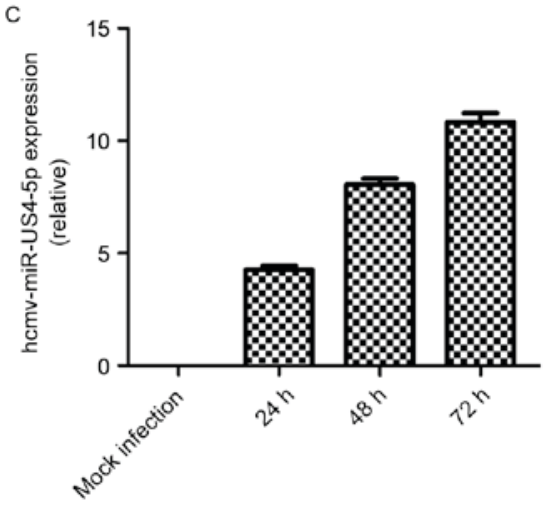

B

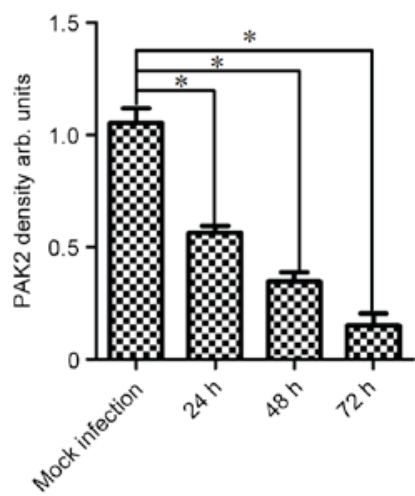

Figure 3. Expression of PAK2 is decreased by HCMV infection at 24 hpi and is decreased with the infection process in HELF cells. (A) PAK2 protein $(60 \mathrm{kDa})$ levels in HCMV infected HELF cells were detected via western blotting at different time points. (B) The PAK2 densitometer values were normal-

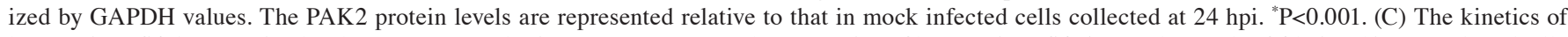
hcmv-miR-US4-1 expression levels were measured using TaqMan assays. The expression of hcmv-miR-US4-5p was detected at 24 hpi and increased gradually as the HCMV-infection process was prolonged. PAK2, p21-activated kinase 2; hcmv, human cytomegalovirus; miR, miRNA; hpi, hours post infection.

$\left({ }^{*} \mathrm{P}<0.001\right)$, which was demonstrated to efficiently inhibit the expression of mature hcmv-miR-US4-5p (Fig. 2B). These results revealed that overexpression of hcmv-miR-US4-5p may specifically downregulate PAK2 protein expression in multiple cells.
Expression of PAK2 is downregulated by HCMV infection. To test if HCMV infection affected PAK2 protein expression in HELF cells, protein levels of PAK2 at mock infection (0), 24, 48 and 72 hpi were detected by western blotting $\left({ }^{*} \mathrm{P}<0.001\right)$. As presented in Fig. 3A and B, compared with mock infected 


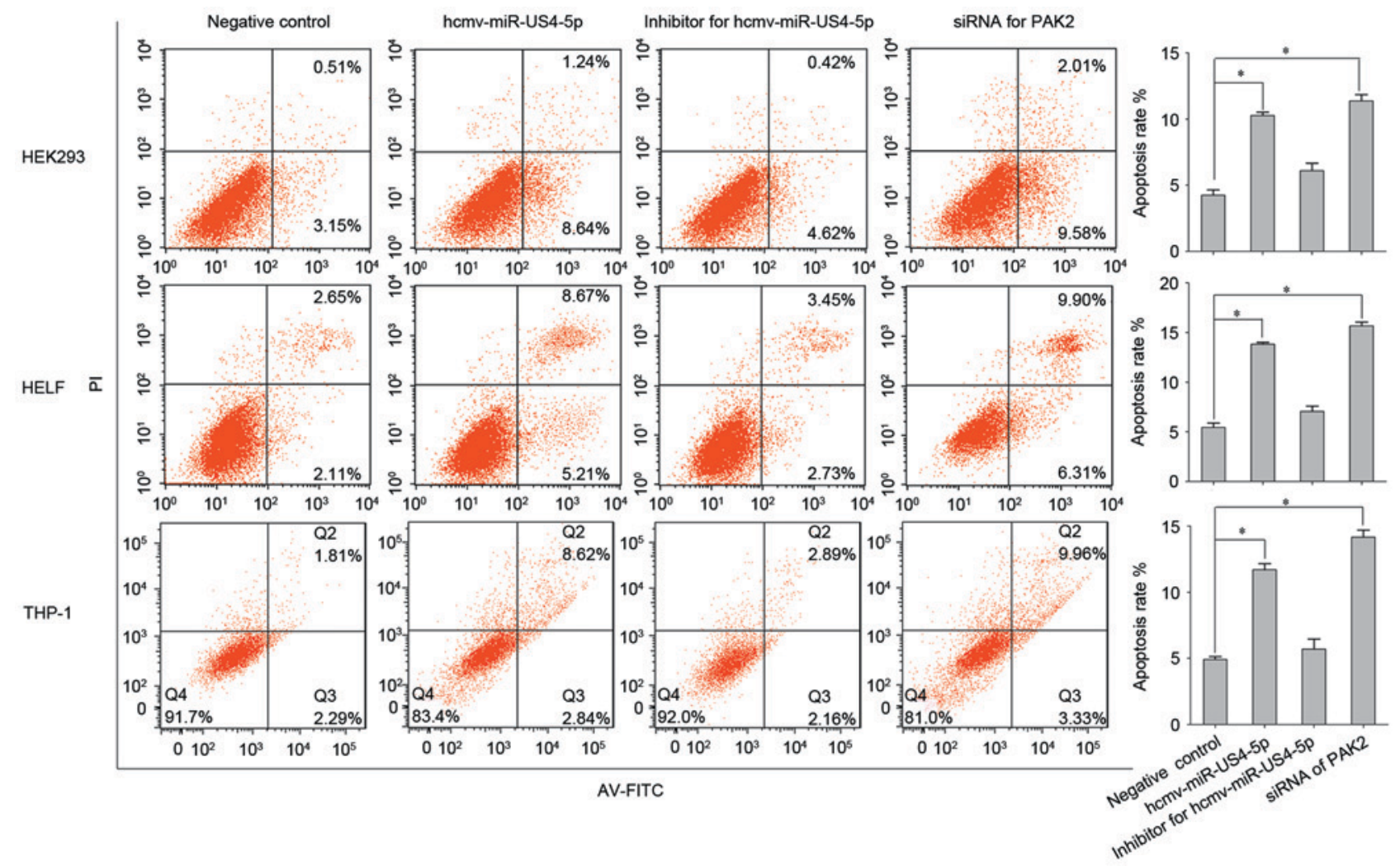

Figure 4. hcmv-miR-US4-5p exhibits a pro-apoptotic effect via inhibition of cellular PAK2 expression. Cells were transfected with miRNA negative control, hcmv-miR-US4-5p mimics, hemv-miR-US4-5p mimics coupled with inhibitor for hemv-miR-US4-5p (inhibitor for hcmv-miR-US4-5p) and siRNAs of PAK2. Cell apoptosis was induced by culturing in medium with $0.1 \% \mathrm{FBS}$ at $24 \mathrm{~h}$ post transfection. Following $24 \mathrm{~h}$, the cells were harvested and analyzed for apoptosis on a flow cytometer. The assays were performed in triplicate wells. Data from three independent repetitions were used for statistical analysis. "P<0.001. PAK2, p21-activated kinase 2; hcmv, human cytomegalovirus; miR, miRNA; siRNA, small interfering RNA; PI, propidium iodide.

cells, the protein level of PAK2 was significantly decreased by $\sim 45 \%$ at $24,70 \%$ at 48 and $80 \%$ at 72 hpi. Furthermore, the expression of homv-miR-US4-5p gradually increased as the HCMV-infection process was prolonged. The quantity of homv-miR-US4-5p in HCMV infected cells at 48 and 72 hpi exhibited a 1.7 and 2.6-fold respective increase compared with the value present at 24 hpi (Fig. 3C). The expression levels of PAK2 in infected HELF cells were negatively associated with the levels of hcmv-miR-US4-5p at different infection points.

hcmv-miR-US4-5p demonstrates a pro-apoptotic effect via inhibition of cellular PAK2 expression. To investigate if inhibition of PAK2 via hemv-miR-US4-5p altered the rate of cell apoptosis, HEK293, HELF and THP-1 cells were transfected with miRNA negative control, hcmv-miR-US4-5p mimic, hcmv-miR-US4-5p mimic coupled with inhibitor for hemv-miR-US4-5p and siRNA of PAK2. A total of $24 \mathrm{~h}$ post-transfection, cell apoptosis was induced by serum starvation, and cells were cultured in medium supplemented with $0.1 \%$ FBS for a further $24 \mathrm{~h}$, and analyzed using annexin $\mathrm{V}$ and PI staining. As presented in Fig. 4, the percentage of apoptotic cells in the three different cell types transfected with hemv-miR-US4-5p or siRNA of PAK2 were significantly greater compared with those transfected with miRNA negative control ("P<0.001). The effect of hcmv-miR-US4-5p on cell apoptosis was almost reversed in cells co-transfected with the inhibitor for hcmv-miR-US4-5p. These results indicated that
hemv-miR-US4-5p promoted cell apoptosis via downregulation of cellular PAK2 expression.

\section{Discussion}

Since the discovery ofHCMV miRNAs (7,11-13), biologicalfunctions of various candidate miRNAs have been studied,including homv-miR-UL112-1 (5,14-16), hemv-miR-US25-1 (16,17), miRUS25-2-3p (18), hemv-miR-UL36 (19), hemv-miR-UL70-3p and hemv-miR-UL148D $(2,20)$. HCMV utilizes miRNAs to regulate its own genes in addition to the host cell genes during infection, to achieve immune evasion, regulation of cellular processes, viral DNA replication and counteracting of cellular apoptosis.

PAK2, termed, p21-activated kinase 2 , is a 58 - to $62-\mathrm{kDa}$ protein that is ubiquitously present in all tissues and cell types $(21,22)$. Various studies have demonstrated that unlike PAK1, PAK2 has a dual function in the regulation of programmed cell death pathways, depending on the specific environment. A 36-kDa C-terminal catalytic PAK2 fragment (PAK2p34), derived from caspase cleavage/activation of PAK2, is associated with Fas and ceramide induced cell death of Jurkat cells, tumor necrosis factor (TNF)- $\alpha$-induced cell death of MCF-7 cells, and UVC light-induced cell death of A431 cells $(23,24)$, indicating that the cleaved/activated PAK2 exhibits a pro-apoptotic function. In addition to the pro-apoptotic function of PAK2p34 following caspase cleavage, full-length PAK2 has an anti-apoptotic function. Expression of constitutively 
active PAK2-T402E, which mimics activated full-length PAK2 in vitro, appears to abrogate the action of PAK2p34 and result in the stimulation of cell survival in BALB3T3 fibroblasts, when exposed to tumor necrosis factor- $\alpha$, growth factor withdrawal and UVC light. The mechanism of suppression of programmed cell death of BALB3T3 fibroblasts seems to be via the phosphorylation of the pro-apoptotic B-cell lymphoma (Bcl)-2 family protein Bcl-2 associated death promoter (Bad), and regulation of the stress-induced activation of extracellular signal-regulated kinase, c-Jun N-terminal kinase and p38 signaling pathways (25). Furthermore, this notion has further been supported by the recent observations that overexpression of miR-134 exhibits a pro-apoptotic function by downregulating PAK2 expression in SKOV3-TR30 cells when stimulated with paclitaxel, which results in phosphorylating Bad into Bad-112 and $-136(26)$.

HCMV contains numerous anti-apoptotic genes, including US28, US4, UL37, UL38 and UL144 (27-32). Various studies have demonstrated that HCMV-encoded miRNAs modulate cell apoptosis. It was previously reported that hcmv-miR-UL148D and hcmv-miR-UL36-5p inhibit apoptosis of infected cells $(29,33)$ and hcmv-miR-US25-1 induces cell apoptosis induced by oxidised low density lipoprotein in endothelial cells (34). The present study demonstrated that overexpression of hcmv-miR-US4-5p directly downregulated PAK2 expression and promoted cell apoptosis, induced by serum starvation, in multiple cells. The PAK2 protein level in infected HELF cells was gradually decreased at 24, 48 and $72 \mathrm{hpi}$, and indicated a negative association with the expression of hcmv-miR-US4-5p. Multiple molecules may be involved in the modulation of PAK2 expression during HCMV infection, however the aforementioned results indicated that hcmv-miR-US4-5p may exhibit a direct inhibitory effect on PAK2 expression. The anti-apoptotic function of PAK2 in cells has led to the hypothesis that hcmv-miR-US4-5p may contribute to release of the virus by promoting apoptosis of infected cells via inhibition of PAK2 at the late stage of natural infection.

However, cell apoptosis is regulated by numerous different factors, including Bad, TNF-related apoptosis inducing ligand, nuclear factor- $\kappa \mathrm{B}, \mathrm{Bcl}-2$ and $\mathrm{Bcl}-2$ associated $\mathrm{X}$ apoptosis regulator. Hcmv-miR-US4-5p was demonstrated to inhibit PAK2 expression and promote cell apoptosis via overexpression prior to infection, however the promotive effects of low levels of naturally-expressed hcmv-miR-US4-5p on cell apoptosis in HCMV-infected cells remain to be elucidated. It may be hypothesized that in conjunction with other pro-apoptotic genes and miRNAs of HCMV, hcmv-miR-US4-5p may contribute to the regulation of cell apoptosis during natural HCMV infection in order to establish a balance between the host cell and virus at a late infection stage.

In conclusion, hcmv-miR-US4-5p was demonstrated to promote apoptosis in various cells by directly inhibiting PAK2 expression. Further investigations are required to fully elucidate the functional role of hcmv-miR-US4-5p in cell apoptosis from HCMV infection, in lytic or latent infection stages.

\section{Acknowledgements}

The present study was supported by the National Natural Science Foundation of China (grant nos. 81171580 and 81201274), the
Specialized Research Fund for the Doctoral Program of Higher Education (grant no. 20112104110012) and the Outstanding Scientific Fund of Shengjing Hospital.

\section{References}

1. Kesson AM and Kakakios A: Immunocompromised children: Conditions and infectious agents. Paediatr Respir Rev 8: 231-239, 2007.

2. Babu SG, Pandeya A, Verma N, Shukla N, Kumar RV and Saxena S: Role of HCMV miR-UL70-3p and miR-UL148D in overcoming the cellular apoptosis. Mol Cell Biochem 393: 89-98, 2014.

3. Fabian MR, Sonenberg N and Filipowicz W: Regulation of mRNA translation and stability by microRNAs. Annu Rev Biochem 79: 351-379, 2010.

4. Cullen BR: Viral and cellular messenger RNA targets of viral microRNAs. Nature 457: 421-425, 2009.

5. Huang T, Cui Y and Zhang X: Involvement of viral microRNA in the regulation of antiviral apoptosis in shrimp. J Virol 88: 2544-2554, 2014.

6. Skalsky RL and Cullen BR: Viruses, microRNAs, and host interactions. Annu Rev Microbiol 64: 123-141, 2010.

7. Stark TJ, Arnold JD, Spector DH and Yeo GW: High-resolution profiling and analysis of viral and host small RNAs during human cytomegalovirus infection. J Virol 86: 226-235, 2012.

8. Huang Y, Qi Y, Ruan Q, Ma Y, He R, Ji Y and Sun Z: A rapid method to screen putative mRNA targets of any known microRNA. Virol J 8: 8, 2011.

9. Nishimura A, Morita M, Nishimura Y and Sugino Y: A rapid and highly efficient method for preparation of competent Escherichia coli cells. Nucleic Acids Res 18: 6169, 1990.

10. Schmittgen TD, Lee EJ, Jiang J, Sarkar A, Yang L, Elton TS and Chen C: Real-time PCR quantification of precursor and mature microRNA. Methods 44: 31-38, 2008.

11. Dunn W, Trang P, Zhong Q, Yang E, van Belle C and Liu F: Human cytomegalovirus expresses novel microRNAs during productive viral infection. Cell Microbiol 7: 1684-1695, 2005.

12. Grey F, Antoniewicz A, Allen E, Saugstad J, McShea A Carrington JC and Nelson J: Identification and characterization of human cytomegalovirus-encoded microRNAs. J Virol 79: 12095-12099, 2005.

13. Pfeffer S, Sewer A, Lagos-Quintana M, Sheridan R, Sander C, Grässer FA, van Dyk LF, Ho CK, Shuman S, Chien M, et al: Identification of microRNAs of the herpesvirus family. Nat Methods 2: 269-276, 2005.

14. Huang Y, Qi Y, Ma Y, He R, Ji Y, Sun Z and Ruan Q: The expression of interleukin-32 is activated by human cytomegalovirus infection and down regulated by hemv-miR-UL112-1. Virol J 10: 51, 2013.

15. Stern-Ginossar N, Elefant N, Zimmermann A, Wolf DG, Saleh N, Biton M, Horwitz E, Prokocimer Z, Prichard M, Hahn G, et al: Host immune system gene targeting by a viral miRNA. Science 317: 376-381, 2007.

16. Stern-Ginossar N, Saleh N, Goldberg MD, Prichard M, Wolf DG and Mandelboim O: Analysis of human cytomegalovirus-encoded microRNA activity during infection. J Virol 83: 10684-10693, 2009.

17. Grey F, Tirabassi R, Meyers H, Wu G, McWeeney S, Hook L and Nelson JA: A viral microRNA down-regulates multiple cell cycle genes through mRNA 5'UTRs. PLoS Pathog 6: e1000967, 2010.

18. Qi M, Qi Y, Ma Y, He R, Ji Y, Sun Z and Ruan Q: Over-expression of human cytomegalovirus miR-US25-2-3p downregulates eIF4A1 and inhibits HCMV replication. FEBS Lett 587: 2266-2271, 2013.

19. Huang Y,Qi Y,Ma Y,HeR,Ji Y,SunZ and Ruan Q: Down-regulation of human cytomegalovirus UL138, a novel latency-associated determinant, by homv-miR-UL36. J Biosci 38: 479-485, 2013.

20. Wang YP, Qi Y, Huang YJ, Qi ML, Ma YP, He R, Ji YH, Sun ZR and Ruan Q: Identification of immediate early gene X-1 as a cellular target gene of hcmv-mir-UL148D. Int J Mol Med 31: 959-966, 2013.

21. Knaus UG, Morris S, Dong HJ, Chernoff J and Bokoch GM: Regulation of human leukocyte p21-activated kinases through G protein-coupled receptors. Science 269: 221-223, 1995.

22. Teo M, Manser E and Lim L: Identification and molecular cloning of a p21cdc42/rac1-activated serine/threonine kinase that is rapidly activated by thrombin in platelets. J Biol Chem 270: 26690-26697, 1995. 
23. Rudel T and Bokoch GM: Membrane and morphological changes in apoptotic cells regulated by caspase-mediated activation of PAK2. Science 276: 1571-1574, 1997.

24. Tang TK, Chang WC, Chan WH, Yang SD, Ni MH and Yu JS: Proteolytic cleavage and activation of PAK2 during UV irradiation-induced apoptosis in A431 cells. J Cell Biochem 70: 442-454, 1998

25. Jakobi R, Moertl E and Koeppel MA: p21-activated protein kinase $\gamma$-PAK suppresses programmed cell death of BALB3T3 fibroblasts. J Biol Chem 276: 16624-16634, 2001.

26. Shuang T, Wang M, Shi C, Zhou Y and Wang D: Down-regulated expression of miR-134 contributes to paclitaxel resistance in human ovarian cancer cells. FEBS Lett 589: 3154-3164, 2015.

27. Arnoult D, Bartle LM, Skaletskaya A, Poncet D, Zamzami N Park PU, Sharpe J, Youle RJ and Goldmacher VS Cytomegalovirus cell death suppressor vMIA blocks Bax- but not Bak-mediated apoptosis by binding and sequestering Bax at mitochondria. Proc Natl Acad Sci USA 101: 7988-7993, 2004.

28. Goldmacher VS, Bartle LM, Skaletskaya A, Dionne CA, Kedersha NL, Vater CA, Han JW, Lutz RJ, Watanabe S, Cahir McFarland ED, et al: A cytomegalovirus-encoded mitochondria-localized inhibitor of apoptosis structurally unrelated to Bcl-2. Proc Natl Acad Sci USA 96: 12536-12541, 1999.
29. Pleskoff O, Casarosa P, Verneuil L, Ainoun F, Beisser P, Smit M, Leurs R, Schneider P, Michelson S and Ameisen JC: The human cytomegalovirus-encoded chemokine receptor US28 induces caspase-dependent apoptosis. FEBS J 272: 4163-4177, 2005.

30. Skaletskaya A, Bartle LM, Chittenden T, McCormick AL, Mocarski ES and Goldmacher VS: A cytomegalovirus-encoded inhibitor of apoptosis that suppresses caspase- 8 activation. Proc Natl Acad Sci USA 98: 7829-7834, 2001.

31. Smith W, Tomasec P, Aicheler R, Loewendorf A, Nemčovičová I, Wang EC, Stanton RJ, Macauley M, Norris P, Willen L, et al: Human cytomegalovirus glycoprotein UL141 targets the TRAIL death receptors to thwart host innate antiviral defenses. Cell Host Microbe 13: 324-335, 2013.

32. Terhune S, Torigoi E, Moorman N, Silva M, Qian Z, Shenk T and Yu D: Human cytomegalovirus UL38 protein blocks apoptosis. J Virol 81: 3109-3123, 2007.

33. Guo X, Huang Y, Qi Y, Liu Z, Ma Y, Shao Y, Jiang S, Sun Z and Ruan Q: Human cytomegalovirus miR-UL36-5p inhibits apoptosis via downregulation of adenine nucleotide translocator 3 in cultured cells. Arch Virol 160: 2483-2490, 2015.

34. Fan J, Zhang W and Liu Q: Human cytomegalovirus-encoded miR-US25-1 aggravates the oxidised low density lipoprotein-induced apoptosis of endothelial cells. Biomed Res Int 2014: 531979, 2014. 